\title{
Determinants of Safety Climate in the Professional Logging Industry
}

\author{
Elise Lagerstrom ${ }^{1, *}$, Sheryl Magzamen ${ }^{1}$, Pete Kines ${ }^{2}{ }^{\oplus}$, William Brazile ${ }^{1}$ and \\ John Rosecrance ${ }^{1} \mathbb{D}$ \\ 1 Department of Environmental and Radiological Health Sciences, Colorado State University, Fort Collins, \\ CO 80523, USA; Sheryl.Magzamen@colostate.edu (S.M.); William.Brazile@colostate.edu (W.B.); \\ John.Rosecrance@colostate.edu (J.R.) \\ 2 Division of Safety Research, National Research Centre for the Working Environment, Lersø Parkallé 105, \\ DK-2100 Copenhagen, Denmark; pki@nfa.dk \\ * Correspondence: Lagerstrome@gmail.com
}

Received: 16 March 2019; Accepted: 13 May 2019; Published: 27 May 2019

\begin{abstract}
Work involving forest logging is considered one of the most dangerous occupations in the world. In the intermountain region of Montana and Idaho in the United States, the extreme terrain, remote location and severe weather conditions escalate risk. Although safety has improved through the development of mechanized equipment, logging tasks continue to be very hazardous. Thus, as with leading companies in other occupational sectors, logging enterprises are beginning to consider safety climate as a useful measure in their safety systems. The purpose of this study was to quantify safety climate within the logging industry of Montana, USA and to identify specific determinants of safety climate. A demographic, musculoskeletal symptom (MSS), and safety climate survey (NOSACQ-50) was administered to 743 professional loggers. Analyses were conducted to determine the association between demographic characteristics, MSS, workplace variables and the scores on five safety climate dimensions (management safety priority and ability, workers' safety commitment, workers' safety priority and risk non-acceptance, peer safety communication, learning and trust in safety ability, and workers' trust in efficacy of safety systems). Variables identified as predictors of safety climate included logging system type, supervisory status, age, years of experience and reported MSS. As safety climate is a leading indicator of workplace safety, if work groups with the lowest safety climate scores can be identified, they could receive targeted safety intervention programs or resources; thereby directing resources to the groups who need it the most, without relying on lagging indicators such as injury and fatality rates.
\end{abstract}

Keywords: safety culture; NOSACQ-50; musculoskeletal symptoms; safety commitment; missed work

\section{Introduction}

Logging is an extremely hazardous occupation and consistently has one of the highest fatality rates in the United States [1,2]. Due to the high rates of injuries and fatalities in the logging industry, logging has been included in the last two decades of the National Occupational Research Agenda (NORA) as a targeted industry subsector with the goal of stimulating innovative research and improved workplace practices [3]. The major objectives of the 2016 update to the NORA included surveillance and providing outreach, communication and partnerships with local companies and industries [3]. Commercial logging has long been considered one of the most dangerous occupations in the United States [4]. In 2016, the Bureau of Labor Statistics (BLS) reported the incidence rates of nonfatal occupational injuries and illnesses in the logging industry as 3.6 per 100 full-time equivalent workers (FTE) [5], and, in 2015, the Census of Fatal Occupational Injuries reported a fatal injury rate of 98 per 100,000 
FTE [1]. In comparison, in 2015, the fatal injury rate for all industries in the United States was 3.4 per 100,00 FTE [1].

The rates and causes of logging injuries may be mediated by regional factors. Factors that can have an effect on occupational injury risk among professional loggers include weather and environmental conditions, heavy equipment use, intensity of physical labor, specific logging practices, terrain slope, as well as safety culture. For example, in the southern United States, the weather is mild, logging operations are highly mechanized and the terrain is relatively flat. Logging in the Pacific Northwest and the intermountain region of Montana and Idaho is characterized by extremely frigid weather (often below freezing), steep terrain that makes some work tasks physically strenuous, the use of more traditional chainsaw felling methods, and remote work locations that are difficult to evacuate injured workers [2,4].

Recently in Montana, and the intermountain region of Montana and Idaho, economic challenges have had a negative effect on logging companies, which have led to greater occupational risks related to longer travel distances, strenuous physical workloads and psychosocial stressors. As a result of the 2008 economic recession in the United States, the demand for timber decreased, mills were closed, and lumber sale prices were depressed. Logging companies faced decreasing profit margins as the cost of harvesting timber remained the same or increased, while sale prices of timber decreased. Timber mills closed forcing timber haulers to drive further distances to unload at mills still open for business. The increase in time and fuel costs to transport logs subsequently decreased the already shrinking profit margins. The psychological stressors of decreasing profit margins [6], long working hours [6-8], and perceived workplace dangers [6] are all present in the logging industry. In a survey of loggers, it was revealed that over $60 \%$ of respondents believed that the financial restrictions and payment were a barrier to workplace health and safety [6]. According to anecdotal opinions from professional loggers, to remain a profitable logging company during times of economic hardship, safety was often sacrificed for productivity and profits [2]. In addition to the workplace stressors of economic concerns and longer working hours, logging workers may also have the perception that they work in a dangerous industry. In studies relating workplace psychosocial stressors to occupational injury rates, jobs with "compromised psychosocial qualities, especially high job demands/workload ... reported more occupational injuries" [9]. These perceptions were documented in a study of health and safety perceptions in Ireland, where over half of the logging workers surveyed believed that forest harvesting work should be described as dangerous [6]. The combination and interaction between these psychosocial stressors may have contributed to the increased injury and fatality rate of the logging industry.

While there have been studies that assess safety perceptions and psychological stressors in the logging industry, there have been no published studies that specifically assess safety climate within the industry. The former logging studies, which have only focused on single factor analyses of economic or psychosocial stressors, are severely limited in their scope, especially in comparison to a safety climate assessment, which provides a broad perspective of multiple dimensions of workers' perceptions of safety.

The construct of safety climate was developed over the last 40 years and measures of safety climate have been gaining popularity as a tool to improve occupational safety. Safety climate can be defined and measured in different ways, however, recent research has converged on the definition of safety climate as a reflection of employee perception of safety in the workplace [10]. Safety climate is often quantified using self-administered survey instruments. There are several different instruments currently available, with each designed to measure safety climate in a specific industry and used as a basis of comparison of specific indicators, or to provide an opportunity to measure the effectiveness of safety interventions [10]. One reason for the interest in safety climate is the desire for measures of leading, rather than lagging, indicators of safety. Safety climate has been demonstrated to be a leading indicator of occupational safety performance and useful in the prevention of injuries and incidents [11]. Zohar (1980) reported that safety climate was designed to distinguish among companies with high and 
low accident and injury rates by assessing various dimensions of organizational climate [11]. Zhang and colleagues (2002), expressed safety climate as the "perceived state of safety in a particular place at a particular time... " [12].

Safety climate investigators have determined that it is useful to measure safety climate prior to the initiation of an intervention and allowing adequate time for climate changes before measuring safety climate post intervention [13]. While examining the link between organizational climate and safety climate, investigators determined that interventions aimed at enhancing the organization's safety would be more successful if the interventions occurred in a positive organizational climate [13]. The investigators of the same research determined that safety climate also had a positive effect on worker motivation and safety compliance, which was imperative for assessing safe work behavior and safety performance [13]. Safety climate assessments are a practical but underutilized method for investigating occupational safety among workers with a history and high risk of occupational injuries. Unfortunately, there are no published studies assessing the safety climate among the population of professional loggers.

The purpose of this study was to determine the level of safety climate among the population of professional loggers in Montana. A second objective was to identify the determinants of safety climate based on surveys of worker demographics, workplace factors, and musculoskeletal symptoms (MSS). The measure of safety climate used this in this study, the Nordic Occupational Safety Climate Questionnaire (NOSACQ-50) [14,15], published thresholds that can be used to categorize safety climate "level" and compare results across groups and time dimensions. By using a validated measure, the results obtained from the Montana logging industry can be compared to the results of safety climate assessments from other industries and as a baseline for logging companies within Montana. As mentioned previously, safety climate is a leading, rather than lagging, indicator of safety. Safety climate, therefore, has the potential to identify work groups which may be more prone to work-related injuries and fatalities. If high-risk groups can be identified through safety climate measures, interventions can be targeted to reach workers at the highest risk prior to actual injuries.

\section{Materials and Methods}

\subsection{Data Acquisition}

A multi-item questionnaire was administered to professional loggers during safety workshops on emergency first-aid in Montana, USA. The training sessions are conducted annually by the Montana Logging Association at various locations across Montana to meet the requirements of the federal Occupational Safety and Health Administration (OSHA). The Montana Logging Association has a memorandum of understanding with OSHA that requires all professional loggers in the Association to participate in annual safety training. In return, OSHA allows the Association to self-manage their occupational health and safety programs. The multi-item survey consisted of three sections that included demographic items, an assessment of MSS, and items intended to assess safety climate. Participation in the study was voluntary, anonymous and only university researchers involved in the project had access to individual results. All loggers attending the safety workshop were invited to participate. Monetary participant incentives were not provided. The researcher's Institutional Review Board on human subjects research approved all study procedures.

Personal information indicating the worker's age, gender and education level were collected via the survey. Occupational information collected through the survey included worker's organizational level (owner, supervisor v. worker), logging system type and whether the logger was a certified logging professional (designation requiring continuing education in safe and environmental logging methods) and number of years working in the logging industry.

The NOSACQ-50 is one metric used to quantify specific areas, or dimensions, of safety climate in the workplace. Several research studies have validated the NOSACQ-50 among numerous occupational cohorts, countries and languages [14]. The developers of the NOSACQ-50 define safety climate as a 
measure of "a workgroup members' shared perceptions of management and workgroup safety related policies, procedures, and practices" [14,15]. To measure safety climate, the Nordic team developed a questionnaire composed of 50 items over seven different dimensions of safety climate. The seven safety climate dimensions covered by the NOSACQ-50 are: (1) management safety priority and ability; (2) management safety empowerment; (3) management safety justice; (4) workers' safety commitment; (5) workers' safety priority and risk non-acceptance; (6) peer safety communication, learning and trust in safety ability; and (7) workers' trust in efficacy of safety systems [15].

The instrument used to assess safety climate in the Montana logging population was based on a modification of the English translation of NOSACQ-50. Modifications were made to shorten the length of the questionnaire such that it would fit into the time allowed during the safety workshop. The modifications included employing five of the seven dimensions of safety climate. The following five dimensions were assessed: management safety priority and ability, workers' safety commitment, workers' safety priority and risk non-acceptance, peer safety communication, learning and trust in safety ability, and workers' trust in efficacy of safety systems. In total, 38 of the original 50 individual climate items were used in the present study. A 4-point Likert scale (1-4) that ranged from strongly disagree (1), to strongly agree (4) was used to score each of the 38 climate items. Within the survey, there were both positively and negatively worded items. In positively worded items, e.g., "Management encourages employees here to work in accordance with safety rules-even when the work schedule is tight", higher scores correspond to a higher level of safety climate. In negatively worded items, e.g., "My coworkers and I accept risk-taking at work", lower scores correspond to a higher level of safety climate.

The presence of MSS in the logging population was assessed through the administration of a modified Standardized Nordic Questionnaire (SNQ) [16]. The modified SNQ queried loggers regarding musculoskeletal symptoms in nine body regions, missed work due to symptoms and seeking medical attention for these symptoms. Details regarding this questionnaire and its use among loggers in Montana are reported elsewhere [17].

\subsection{Data Analyses}

Descriptive and frequency statistics were developed for the demographic variables. Years of logging work experience were converted into a categorical variable by decades of experience. Two dichotomous variables were developed to classify workers who experienced MSS in any anatomical region (Yes/No), or missed work due to MSS in the past year (Yes/No).

Dimension scores for NOSACQ-50 were examined and scored in accordance with established guidelines [15]. A climate score for each dimension was determined. Scores for negative (alternatively) worded items were reversed when computing dimension scores. Scores on each safety climate dimension were determined for logging industry leaders (owners and supervisors grouped together) as well as for workers.

T-tests were conducted to establish the presence of statistically significant differences in safety climate dimension scores relative to leader versus worker status. Additionally, t-tests were conducted to determine the presence of significant differences in safety climate dimension scores based on the presence of any MSS status or lost work related to MSS.

A categorical response variable was developed for the range of safety climate scores consistent with those published by the National Research Centre for the Working Environment in Denmark [15]. Safety climate dimension scores greater than 3.30 , on the scale of $1-4$, indicate that the safety climate level of the workplace is good. Safety climate dimension scores between 3 to 3.30 are considered fairly good safety climate, and scores less than 3.00 are considered low to fairly low [15].

Multinomial logistic regression was conducted to determine demographic, workplace, and injury variables that were associated with the categorical levels of the safety climate dimension scores. Logistic regression models were computed for each of the five safety climate dimensions. Variables entered into the model contained logging system type, leader/non-leader status, certified as an accredited 
logging professional (yes/no), education level, age, work experience in logging, and whether the logger reported any MSS. All data analyses were conducted using SAS 9.4 [18]. A statistical significance level was established as $p<0.05$.

\section{Results}

\subsection{Respondent demographics}

Although 1,059 loggers participated in the safety training workshops, only 743 loggers $(70.2 \%)$ participated in the safety climate survey. The mean age of responding loggers was 46 (SD: 13.7) while the mean work experience in logging was 22 years (SD: 14.1). Nearly half $(48.1 \%)$ of loggers reported work-related MSS in the past 12-months, and 6\% of the loggers indicated that they missed work in the past year due to MSS (Table 1).

Table 1. Montana logging survey 2017: Respondent demographics.

\begin{tabular}{lc}
\hline \multicolumn{1}{c}{ Demographic/Workplace Factor } & N Total = 743 \\
\hline Age & Mean: 45.88 (SD: 13.67; Range: $15-79 ; \mathrm{n}=688)$ \\
\hline Years in the Logging Industry & Mean: 21.96 (SD: 14.11; Range: 0-55; $\mathrm{n}=662)$ \\
\hline Owner or Supervisor & $284(38.2 \%)$ \\
Yes & $412(55.5 \%)$ \\
No & $47(6.3 \%)$ \\
Missing & \\
\hline Accredited Logging Professional (ALP) & $174(23.4 \%)$ \\
Yes & $414(55.7 \%)$ \\
No & $155(20.9 \%)$ \\
Missing & \\
\hline Highest Education Level Achieved & $55(7.4 \%)$ \\
Some High School & $410(55.2 \%)$ \\
High School Diploma Awarded & $179(24.1 \%)$ \\
Some College & $59(7.9 \%)$ \\
Bachelor Degree or Higher & $40(5.4 \%)$ \\
Missing & \\
\hline Primary Logging System Type & $80(10.8 \%)$ \\
Conventional & $408(54.9 \%)$ \\
Mechanical & $28(3.8 \%)$ \\
Both & $227(30.6 \%)$ \\
Missing & \\
\hline Musculoskeletal Symptoms & $274(48.1 \%)$ \\
MSS in any body region & $34(6.0 \%)$ \\
Lost work due to MSS &
\end{tabular}

\subsection{Safety Climate Analyses and Categorization}

The results of the safety climate survey are presented in Table 2 . Safety climate dimension one (management safety priority and ability) had the highest mean score of 3.40, while dimension four (workers' safety commitment) had a very similar sore at 3.39. Safety climate dimension six (peer safety communication, learning and trust in safety ability) and dimension seven (workers' trust in the efficacy of safety systems) both had good climate scores of 3.34. Safety climate dimension five (workers' safety priority and risk non-acceptance) was determined to have the lowest mean climate score at 3.10, indicating it was not in the "good" climate level category. Leaders in the logging industry had higher scores on all safety dimensions assessed as compared to safety climate scores of logging workers. The difference between safety climate scores for logging leaders and logging workers was statistically significant for dimensions one and four. 
Table 2. Montana logging survey 2017: Safety climate survey results by dimension.

\begin{tabular}{|c|c|c|c|c|c|c|c|c|c|c|}
\hline \multirow[t]{2}{*}{ Measure } & \multicolumn{2}{|c|}{$\begin{array}{l}\text { Dimension 1* } \\
\text { Management } \\
\text { Safety Priority } \\
\text { and Ability }\end{array}$} & \multicolumn{2}{|c|}{$\begin{array}{l}\text { Dimension } 4 \\
\text { Workers' Safety } \\
\text { Commitment }\end{array}$} & \multicolumn{2}{|c|}{$\begin{array}{c}\text { Dimension } 5 \\
\text { Workers' Safety } \\
\text { Priority and Risk } \\
\text { Non-Acceptance }\end{array}$} & \multicolumn{2}{|c|}{$\begin{array}{c}\text { Dimension } 6 \\
\text { Peer Safety } \\
\text { Communication, Learning } \\
\text { and Trust in Safety Ability }\end{array}$} & \multicolumn{2}{|c|}{$\begin{array}{c}\text { Dimension } 7 \\
\text { Workers' Trust in } \\
\text { the Efficacy of } \\
\text { Safety Systems }\end{array}$} \\
\hline & Leader & Worker & Leader & Worker & Leader & Worker & Leader & Worker & Leader & Worker \\
\hline Dimension Score & $3.44 * *$ & $3.37^{* *}$ & $3.44^{* *}$ & $3.37^{* *}$ & 3.14 & 3.07 & 3.36 & 3.32 & 3.36 & 3.33 \\
\hline Cronbach's Alpha & 0.86 & 0.89 & 0.72 & 0.70 & 0.72 & 0.76 & 0.90 & 0.92 & 0.86 & 0.89 \\
\hline
\end{tabular}

${ }^{*}$ NOSACQ-50 dimensions two and three were not included in the survey; ${ }^{* *} t$-test significant, $p<0.05$ for leaders (owners/supervisors) verses workers.

\subsection{Safety Climate and MSS Reporting}

Statistical tests were conducted to assess a statistically significant difference in dimension scores among those who did or did not indicate the presence of MSS in the previous 12-months (Table 3). Logging leaders who reported MSS had a statistically significant lower score on dimension five $(p=0.05)$ as compared to leaders not reporting MSS. Workers that indicated MSS had significantly lower scores on both dimension one ( $p=0.03)$, and dimension five $(p=0.01)$, as compared to logging workers that did not indicate the presence of MSS. There were no statistically significant differences in safety climate dimension scores for logging leaders or logging workers that did or did not miss work because of MSS.

Table 3. Montana logging survey 2017: Safety climate dimension scores by musculoskeletal symptom status (MSS).

\begin{tabular}{|c|c|c|c|c|c|c|}
\hline $\begin{array}{c}\text { Supervisory } \\
\text { Status }\end{array}$ & MSS & $\begin{array}{c}\text { Dimension } 1 * \\
\text { Management } \\
\text { Safety Priority } \\
\text { and Ability }\end{array}$ & $\begin{array}{c}\text { Dimension } 4 \\
\text { Workers' Safety } \\
\text { Commitment }\end{array}$ & $\begin{array}{c}\text { Dimension } 5 \\
\text { Workers' Safety } \\
\text { Priority and Risk } \\
\text { Non-Acceptance }\end{array}$ & $\begin{array}{c}\text { Dimension } 6 \\
\text { Peer Safety } \\
\text { Communication, Learning } \\
\text { and Trust in Safety Ability }\end{array}$ & $\begin{array}{c}\text { Dimension } 7 \\
\text { Workers' trust in } \\
\text { the Efficacy of } \\
\text { Safety Systems }\end{array}$ \\
\hline \multirow{4}{*}{$\begin{array}{l}\text { Leaders } \\
\text { (owners/ } \\
\text { supervisors) }\end{array}$} & Any MSS & 3.46 & 3.47 & 3.09 & 3.35 & 3.33 \\
\hline & $\begin{array}{c}\text { T-test } \\
p \text {-value }\end{array}$ & NS & NS & 0.0498 & NS & NS \\
\hline & No Missed Work Days & 3.45 & 3.45 & 0.16 & 3.36 & 3.36 \\
\hline & $\begin{array}{c}\text { T-test } \\
p \text {-value }\end{array}$ & NS & NS & NS & NS & NS \\
\hline \multirow{5}{*}{ Workers } & No MSS & 3.43 & 3.38 & 3.15 & 3.33 & 3.34 \\
\hline & Any MSS & 3.30 & 3.36 & 3.01 & 3.29 & 3.30 \\
\hline & T-test & & & & & \\
\hline & $p$-value & 0.0283 & NS & 0.0128 & NS & NS \\
\hline & No Missed Work Days & 3.38 & 3.38 & 3.09 & 3.32 & 3.33 \\
\hline
\end{tabular}

* NOSACQ-50 dimensions two and three were not included in the survey.

\subsection{Regression Results: Demographic and Workplace Factors Predicting Safety Climate}

Multinomial logistic regression was used to examine differences in predictors of the three safety climate dimension categories: good, fairly good, and low (Table 4). In dimension one, two variables were significant in differentiating respondents with a low safety climate dimension score from those with a good safety climate score: supervisory status and decades of experience. Workers were nearly four times (OR $=3.98,95 \%$ CI: 1.40-11.35) as likely to be categorized in the lowest level of safety climate than leaders. In comparison to workers who did not finish high school, workers who had a high school diploma or some college had 0.16 (CI: 0.04-0.66) and 0.15 (CI: 0.03-0.68) decreased odds, respectively of being placed in the lowest category of safety climate, respectively. As education increased from no high school diploma to some college, there were decreased odds of being in the low safety climate categorization for dimension one. In dimension four, workers using mechanical logging systems were over twice (OR $=2.25,95 \%$ CI: $1.00-5.06)$ as likely to be categorized as having a 'fairly good' perception of safety climate rather than 'good' safety climate. In dimension five, two variables were significantly associated with differentiation between low and good levels of safety climate, and a single variable was associated with increased odds of a respondent's placement in the 'fairly good' safety climate categorization. 
Table 4. Montana logging survey 2017: Multinomial logistic regression results.

\begin{tabular}{|c|c|c|c|c|c|c|c|c|c|c|}
\hline \multirow{3}{*}{ Demographic/Workplace Factor } & \multicolumn{10}{|c|}{ Likelihood Relative to Referent- "Good" Safety Climate Dimension Score } \\
\hline & \multicolumn{2}{|c|}{ Dimension 1} & \multicolumn{2}{|c|}{ Dimension 4} & \multicolumn{2}{|c|}{ Dimension 5} & \multicolumn{2}{|c|}{ Dimension 6} & \multicolumn{2}{|c|}{ Dimension 7} \\
\hline & $\begin{array}{l}\text { Fairly Good } \\
\text { OR }(95 \% \text { CI }\end{array}$ & $\begin{array}{c}\text { Low } \\
\text { OR }(95 \% \mathrm{CI})\end{array}$ & $\begin{array}{l}\text { Fairly Good } \\
\text { OR }(95 \% \text { CI }\end{array}$ & $\begin{array}{c}\text { Low } \\
\text { OR }(95 \% \text { CI })\end{array}$ & $\begin{array}{l}\text { Fairly Good } \\
\text { OR }(95 \% \text { CI }\end{array}$ & $\begin{array}{c}\text { Low } \\
\text { OR }(95 \% \mathrm{CI})\end{array}$ & $\begin{array}{l}\text { Fairly Good } \\
\text { OR }(95 \% \text { CI }\end{array}$ & $\begin{array}{c}\text { Low } \\
\text { OR }(95 \% \mathrm{CI})\end{array}$ & $\begin{array}{l}\text { Fairly Good } \\
\text { OR }(95 \% \text { CI })\end{array}$ & $\begin{array}{c}\text { Low } \\
\text { OR }(95 \% \mathrm{CI})\end{array}$ \\
\hline \multicolumn{11}{|l|}{ Primary Logging System: } \\
\hline Conventional & 1.00 & 1.00 & 1.00 & 1.00 & 1.00 & 1.00 & 1.00 & 1.00 & 1.00 & 1.00 \\
\hline Mechanical & $1.82(0.77-4.30)$ & $0.66(0.24-1.85)$ & $2.25(1.00-5.06)$ & $1.16(0.28-4.86)$ & $3.46(1.28-9.33)$ & $2.00(0.87-4.61)$ & $1.76(0.84-3.71)$ & $2.18(0.65-7.33)$ & $2.37(0.99-5.67)$ & $0.80(0.28-2.34)$ \\
\hline \multicolumn{11}{|l|}{ Supervisory Status } \\
\hline Owner/Supervisor & 1.00 & 1.00 & 1.00 & 1.00 & 1.00 & 1.00 & 1.00 & 1.00 & 1.00 & 1.00 \\
\hline Worker & $1.10(0.56-2.15)$ & $3.98(1.40-11.35)$ & $1.40(0.74-2.65)$ & $3.49(0.96-12.71)$ & $0.95(0.43-2.09)$ & $1.48(0.70-3.13)$ & $1.78(0.96-3.31)$ & $1.66(0.65-4.21)$ & $1.42(0.73-2.77)$ & $0.86(0.32-2.29)$ \\
\hline \multicolumn{11}{|l|}{ Accredited Logging Professional } \\
\hline Yes & $1.33(0.70-2.52)$ & $0.43(0.14-1.28)$ & 1.00 & 1.00 & 1.00 & 1.00 & 1.00 & 1.00 & 1.00 & 1.00 \\
\hline No & 1.00 & 1.00 & $0.97(0.51-1.82)$ & $2.71(0.89-8.21)$ & $1.42(0.64-3.14)$ & $1.85(0.87-3.93)$ & $0.85(0.46-.55)$ & $0.52(0.20-1.39)$ & $0.86(0.46-1.63)$ & $0.61(0.22-1.66)$ \\
\hline \multicolumn{11}{|l|}{ Education Level } \\
\hline Did not finish High School & 1.00 & 1.00 & 1.00 & 1.00 & 1.00 & 1.00 & 1.00 & 1.00 & 1.00 & 1.00 \\
\hline High School Diploma & $0.57(0.16-2.05)$ & $0.16(0.04-0.66)$ & $2.16(0.55-8.41)$ & $0.28(0.06-1.36)$ & $1.41(0.23-8.77)$ & $0.33(0.08-1.33)$ & $0.65(0.21-2.05)$ & $0.42(0.09-1.99)$ & $0.92(0.27-3.14)$ & $0.48(0.10-2.38)$ \\
\hline Some College & $0.47(0.13-1.78)$ & $0.15(0.03-0.68)$ & $2.66(0.65-10.94)$ & $0.37(0.07-2.04)$ & $1.94(0.30-12.53)$ & $0.33(0.08-1.45)$ & $0.40(0.12-1.34)$ & $0.31(0.06-1.65)$ & $0.75(0.21-2.75)$ & $0.75(0.21-2.75)$ \\
\hline B.S. or Higher & $0.92(0.21-3.96)$ & $0.25(0.03-1.88)$ & $3.47(0.73-16.56)$ & - & $0.64(0.08-5.45)$ & $0.67(0.13-3.41)$ & $0.40(0.10-1.65)$ & $0.49(0.07-3.44)$ & $0.64(0.14-3.01)$ & $2.31(0.36-14.98)$ \\
\hline Age & $1.01(0.98-1.05)$ & $1.02(0.97-1.07)$ & $1.00(0.96-1.03)$ & $1.04(0.98-1.11)$ & $1.02(0.98-1.06)$ & $0.95(0.92-0.99)$ & $1.03(1.00-1.07)$ & $1.04(0.99-1.09)$ & $1.01(0.98-1.05)$ & $0.94(0.89-1.00)$ \\
\hline \multicolumn{11}{|l|}{ Years of Experience in Logging } \\
\hline $0-10$ & 1.00 & 1.00 & 1.00 & 1.00 & 1.00 & 1.00 & 1.00 & 1.00 & 1.00 & 1.00 \\
\hline $11-20$ & $0.53(0.24-1.20)$ & $0.78(0.24-2.54)$ & $0.77(0.35-1.71)$ & $0.39(0.08-1.78)$ & $0.51(0.18-1.44)$ & $0.99(0.38-2.61)$ & $0.59(0.27-1.33)$ & $0.28(0.08-0.94)$ & $0.83(0.34-2.02)$ & $1.09(0.34-3.51)$ \\
\hline $21-30$ & $0.41(0.16-1.09)$ & $1.22(0.32-4.62)$ & $0.84(0.33-2.15)$ & $0.40(0.07-2.19)$ & $0.45(0014-1.40)$ & $0.87(0.28-2.74)$ & $0.41(0.16-1.06)$ & $0.45(0.13-1.64)$ & $0.58(0.21-1.62)$ & $0.45(0.08-2.42)$ \\
\hline $31-40$ & $0.40(0.11-1.43)$ & $1.04(0.19-5.66)$ & $1.67(0.50-5.65)$ & $0.50(0.06-4.21)$ & $0.35(0.081-1.55)$ & $0.88(0.20-3.83)$ & $0.42(0.13-1.40)$ & $0.18(0.03-1.11)$ & $0.98(0.26-3.65)$ & $1.26(0.16-9.70)$ \\
\hline $40+$ & $0.32(0.07-1.51)$ & - & $1.19(0.26-5.42)$ & - & $0.32(0.06-1.86)$ & $0.56(0.08-3.77)$ & $0.37(0.08-1.73)$ & $0.12(0.01-1.78)$ & $0.47(0.09-2.40)$ & $0.60(0.03-10.73)$ \\
\hline \multicolumn{11}{|l|}{ MSS Status } \\
\hline No symptoms & 1.00 & 1.00 & 1.00 & 1.00 & 1.00 & 1.00 & 1.00 & 1.00 & 1.00 & 1.00 \\
\hline Symptoms & $0.89(0.51-1.56)$ & $2.07(0.90-4.76)$ & $0.79(0.50-1.35)$ & $1.49(0.51-4.34)$ & $1.15(0.58-2.25)$ & $2.98(1.55-5.72)$ & $1.06(0.62-1.81)$ & $1.29(0.58-2.89)$ & $0.96(0.55-1.68)$ & $1.89(0.79-4.49)$ \\
\hline
\end{tabular}


The odds ratio for a one-unit increase in the variable age was $0.95(95 \% \mathrm{CI}=0.92-0.99)$ for low safety versus good safety climate scores. Thus, as age increased, respondents were less likely to be categorized in the low safety climate group. Also, in dimension five, respondents using mechanical logging systems were over three times more likely to report a score in the 'fairly good' safety climate category rather than the 'good' safety climate category, and respondents with low safety climate scores were almost three times more likely to report MSS than people with a good level of safety climate. In dimension seven, age was the only significant demographic predictor of safety climate categorization between respondents having a low versus a good level of safety climate. The odds ratio for a one-unit increase in the variable age was 0.94 for having a low vs. a good safety climate score. Younger ages were associated with categorization in the low safety climate group.

\section{Discussion}

The purpose of this study was to quantify safety climate within the logging industry of Montana and to identify specific determinants of safety climate. When all responses were considered, dimension one, management safety priority and ability, had the highest mean overall score, followed by dimension four, workers' safety commitment, dimension seven, workers' trust in efficacy of safety systems, and dimension six, peer safety communication. Dimension five, workers' safety priority and risk non-acceptance, had the lowest mean score and, when interpreted and categorized according to published standards, was the only dimension found to not fall into the "good" category.

Reoccurring predictors of safety climate within the population of loggers in the present study included logging system type and age. In dimension four (workers' safety commitment) and dimension five (workers' safety priority and risk non-acceptance), there were increased odds of loggers using mechanical systems being assigned to the fairly good category of safety climate as compared to the good category of safety climate (OR: 2.25 and OR: 3.46, respectively). That is, loggers using mechanical logging systems having lower safety commitment and more likely to accept risks than loggers using conventional logging systems. In both dimensions five and seven (workers' trust in the efficacy of safety systems), as age increased, loggers were less likely to be categorized into the low safety climate category. There was only one dimension where positive MSS status was significantly associated with low safety climate. In dimension five, which is workers' safety priority and risk non-acceptance, workers who reported work-related MSS were nearly three times more likely to be assigned to the low category of safety climate than the good category, meaning, loggers who experienced MSS in the past year were more likely to have low safety priorities and accept risks in the workplace than loggers who did not report MSS.

While not significant in the regression model, the disparity between leaders' and workers' safety climate scores is of interest. Across all five dimensions, leaders (owners/supervisors) of logging companies had higher safety climate scores than workers, and in two dimensions, when workers were compared directly to leaders, workers had significantly lower responses. The significant differences were found in dimensions one (management safety priority and ability) and four (workers' safety commitment). The disparity between leaders' views of their own safety priority versus workers' views of leaders' safety priority deserves further investigation. In addition, it may be prudent for leaders to realize that their workers have a significantly different (and lower) view of their safety priorities than how they rate themselves. The difference in safety climate between leaders and workers may be attributed to the difference in primary job duties and work environment. In general, leaders have an increased emphasis on adherence to policy and procedures rather than practice. The difference in safety climate between leaders and workers may also indicate dissociation or distancing in the relationship between leadersand workers, signaling the need for greater management involvement. In a case study using construction workers in Las Vegas a similar disparity between the safety perception of workers and leaders was observed. The study's authors found that there was a notable, but not significant, difference between how workers/foremen responded to a question regarding prioritizing safety over production in comparison to superintendents/executives. The authors found 
that superintendents/executives responded more in favor to safety over production in comparison to workers who were less likely to believe safety was prioritized over production [19].

While mechanization of the logging industry has been associated with decreasing injuries $[6,7,20]$, it is also associated with increased productivity pressure and excessive shift length compared to conventional logging [6]. In the present study, a significant difference was found in the odds of mechanical logging systems being associated with lower categories of safety climate than conventional logging workers. The difference in safety climate scores between workers employed in conventional versus mechanical logging operations may be due to the teamwork and interaction between employees on conventional sites. Workers in mechanical logging systems often work in enclosed cabs and may be distanced from other workers, while conventional workers often work in proximity to each other, reinforcing communication and the team environment.

Researchers studying safety climate have identified many different factors which influence safety climate in a workplace. Recently, investigators have found significant associations between safety climate and age, job type, company size, industry, and education level of the workforce [21-25]. Authors of a cross-sectional study of Danish workers [21] found that there was a significant association between lower safety climate ratings among workers aged 18-29 in comparison to workers at the same workplace in older age groups [21]. The finding that younger workers perceive safety climate more negatively than older workers at the same workplace has been confirmed in studies of nuclear power plants [22,23], as well as a university laboratory [24], and the construction industry [25]. This association between increasing age and higher perceptions of safety climate was seen in the present study in dimensions five and seven.

In addition to age, the Danish authors [21] also found an association between the predictor variables of education, job type, size of company, and industrial sector and safety climate [21]. Higher education levels were associated with higher levels of management safety empowerment and co-worker safety priority, and salaried workers were found to have more favorable safety climate ratings than that of skilled or unskilled labor [21]. Interestingly, the Danish investigators found no association between length of employment and safety climate rating [21]. In the present study, increased education was associated with decreased likelihood of low safety climate in dimension one, and no consistent association between worker experience and safety climate.

When comparing the results of the present study to research performed in other labor-intensive industries, logging workers had higher safety climate scores than both carpenters and construction workers. Lipscomb, Schoenfisch, and Cameron (2015) performed an analysis of the safety climate of carpenters from Washington State using three of the NOSACQ-50 dimensions. Two of the three dimensions surveyed overlapped with the methodology of the present study. Lipscomb et al. found that the mean worker safety priority score was 2.90 , and mean peer safety communication score was 3.11 [26]. This is lower than the results found in the present study, which were 3.07 and 3.32, respectively.

In comparison to a study of Norwegian construction workers [27], the current study found that logging workers had higher safety climate scores across all dimensions surveyed. Interestingly, the lowest dimension score for both studies was dimension five: workers' safety priority and risk non-acceptance. In the study of Norwegian construction workers, the mean score for dimension five was 2.89 [27], whereas in the present study, the mean score was 3.07.

\section{Limitations}

There are several limitations given the research design in the present study. The population was limited to professional loggers participating in an annual mandatory safety-training program in Montana. It is difficult to determine the extent of selection bias, as the authors had no information on non-respondents. Thus, the sample only represents the population sample attending the safety-training course. However, it is known that 743 of the 1059 (70\% response rate) members of the logging organization expected at the training program participated. Because the logging conditions in Montana are specific to the unique characteristics of the environment, steep grades of forests being harvested 
and worker demographics, generalization to the logging industry outside of this region should be done with caution. In addition, due to limitations in study design and the retrospective nature of the research, the authors were unable to determine the temporality of the relationship between MSS and safety climate. The authors were unable to establish if the MSS occurred first, leading to changes in workers' perception of safety or if workers' perception of safety and their willingness to accept it led to MSS.

\section{Conclusions}

The investigators of this study identified that the safety climate of a worksite is not uniform but varies significantly based upon determinants such as socio-demographic factors. This may have important implications for the identification and reduction of risk in occupational settings. According to previous studies, there is a correlation between the perceived risk at a workplace and the occurrence of injury claims. The advantage of measuring safety climate rather than injury claims is the ability to predict and confront risks prior to the occurrence of an injury or fatality. For this reason, measuring safety climate and making appropriate changes to a workplace is a proactive step at injury prevention. Just as it is important to understand trends in workplace injuries and fatalities, understanding the socio-demographic and workplace determinants of safety climate will allow for the development of interventions which will reduce workplace risk and injury. By using a proactive measurement technique, such as safety climate, it is possible to identify demographic and workplace factors which place individuals at higher risk. The overall objective is to create targeted intervention strategies without having to wait for a catastrophic event such as a workplace injury or fatality; thus moving toward proactive injury prevention.

As indicated in the results of the study, the authors provide a quantitative evaluation of the current safety climate in the logging industry. The methods of the current study are novel in the context of the logging industry, and continued research is desperately needed due to continued high rates of injuries and fatalities among professional loggers. The data and subsequent results obtained during this study provide a baseline measure of both musculoskeletal symptoms and safety climate, which can be used as a standard of comparison after the application of safety interventions.

Moving forward, injury prevention efforts in the logging industry should focus on sustaining the safety climate of the logging industry, specifically targeting the mismatch between leaders (owners/supervisors) versus worker safety perceptions, and the association between MSS and safety climate.

Quantifying the current safety climate of the logging population and investigating determinants of safety climate is needed to identify possible areas and opportunities for future interventions. Measuring leading indicators, such as safety climate, is a step towards proactive injury surveillance and control. As safety climate is a leading indicator of workplace safety, if work groups with the lowest safety climate scores can be identified, they could receive targeted safety intervention programs or resources; thereby directing resources to the groups who need it the most, without relying on lagging indicators such as injury and fatality rates. In addition, measuring the safety climate of Montana loggers will support the NORA for AFF by providing industry surveillance and will help determine readiness for future safety interventions.

Author Contributions: Conceptualization, E.L., P.K. and J.R.; Formal analysis, E.L., S.M., P.K., W.B. and J.R.; Funding acquisition, E.L., S.M. and J.R.; Methodology, E.L., S.M., P.K., W.B. and J.R.; Project administration, E.L. and J.R.; Supervision, S.M., P.K., W.B. and J.R.; Writing - original draft, E.L.; Writing - review \& editing, E.L., S.M., P.K., W.B. and J.R.

Funding: This research was supported in part by the National Institute for Occupational Safety and Health (NIOSH) Mountain and Plains Education and Research Center, grant number 5T42OH009229 and NIOSH funded High Plains Intermountain Center for Agricultural Health and Safety, grant number U54 OH008085. The content is the responsibility of the authors and does not necessarily represent the official views of NIOSH.

Acknowledgments: The authors are deeply grateful for the cooperation and partnership that has been formed with the Montana Logging Association. This research would not have been possible without the synergetic 
collaboration between industry and academia. We hope that this research will lead to interventions, which will benefit the loggers who work tirelessly to provide for their families and meet the nation's demand for this resource.

Conflicts of Interest: The authors declare no conflict of interest.

\section{References}

1. U.S. Bureau of Labor Statistics. Census of Fatal Occupational Injuries (CFOI)-Current and revised data. Available online: https://www.bls.gov/iif/oshcfoi1.htm\#rates (accessed on 3 March 2019).

2. Lagerstrom, E.; Magzamen, S.; Rosecrance, J. A mixed-methods analysis of logging injuries in Montana and Idaho. Am. J. Ind. Med. 2017, 60, 1077-1087. [CrossRef] [PubMed]

3. National Occupational Research Agenda (NORA) Agriculture, Forestry and Fishing (AgFF) Sector Council. National Agriculture, Forestry and Fishing Agenda. 2016. Available online: https://www.cdc.gov/nora/pdfs/ NORA-AgFF-Revised-Agenda-Sept2016.pdf (accessed on 10 February 2019).

4. United States Department of Labor, Occupational Safety and Health Administration (O.S.H.A.). Safety and Health Topics: Logging. Available online: https://www.osha.gov/SLTC/logging/ (accessed on 3 March 2019).

5. U.S. Bureau of Labor Statistics. Industry Injury and Illness Data-2016. Available online: https://www.bls. gov/iif/oshsum.htm\#16Summary_News_Release (accessed on 3 March 2019).

6. Nieuwenhuis, M.; Lyons, M. Health and safety issues and perceptions of forest harvesting contractors in Ireland. J. For. Eng. 2002, 22, 69-76. [CrossRef]

7. Axelsson, S.-Å. The mechanization of logging operations in Sweden and its effect on occupational safety and health. J. For. Eng. 1998, 9, 25-31.

8. Lilley, R.; Feyer, A.-M.; Kirk, P.; Gander, P. A survey of forest workers in New Zealand: Do hours of work, rest, and recovery play a role in accidents and injury? J. Saf. Res. 2002, 33, 53-71. [CrossRef]

9. Nakata, A.; Ikeda, T.; Takahashi, M.; Haratani, T.; Hojou, M.; Fujioka, Y.; Swanson, N.G.; Araki, S. Impact of psychosocial job stress on non-fatal occupational injuries in small and medium-sized manufacturing enterprises. Am. J. Ind. Med. 2006, 49, 658-669. [CrossRef] [PubMed]

10. Schwatka, N.V.; Hecker, S.; Goldenhar, L.M. Defining and measuring safety climate: A review of the construction industry literature. Ann. Occup. Hyg. 2016, 60, 537-550. [CrossRef]

11. Zohar, D. Safety climate in industrial organizations: Theoretical and applied implications. J. Appl. Psychol. 1980, 65, 96. [CrossRef]

12. Zhang, H.; Wiegmann, D.A.; von Thaden, T.L.; Sharma, G.; Mitchell, A.A. Safety Culture: A Concept in Chaos? Proc. Hum. Factors Ergon. Soc. Ann. Meet. 2002, 46, 1404-1408. [CrossRef]

13. Neal, A.; Griffin, M.A.; Hart, P.M. The impact of organizational climate on safety climate and individual behavior. Saf. Sci. 2000, 34, 99-109. [CrossRef]

14. Kines, P.; Lappalainen, J.; Mikkelsen, K.L.; Olsen, E.; Pousette, A.; Tharaldsen, J.; Tómasson, K.; Törner, M. Nordic Safety Climate Questionnaire (NOSACQ-50): A new tool for diagnosing occupational safety climate. Int. J. Ind. Ergon. 2011, 41, 634-646. [CrossRef]

15. Kines, P.; Lappalainen, J.; Mikkelsen, K.L.; Olsen, E.; Pousette, A.; Tharaldsen, J.; Tómasson, K.M.T. The Nordic Safety Climate Questionnaire (NOSACQ-50). Available online: http://www.arbejdsmiljoforskning. $\mathrm{dk} / \mathrm{da} /$ publikationer/spoergeskemaer/nosacq-50 (accessed on 3 March 2019).

16. Kuorinka, I.; Jonsson, B.; Kilbom, A.; Vinterberg, H.; Biering-Sorensen, F.; Andersson, G.; Jorgensen, K. Standardised Nordic questionnaires for the analysis of musculoskeletal symptoms. Appl. Ergon. 1987, 18, 233-237. [CrossRef]

17. Lagerstrom, E.; Magzamen, S.; Brazile, W.; Rosecrance, J. Active Surveillance of Musculoskeletal Disorder Symptoms in the Development of Safety Interventions for Professional Loggers. Safety 2019, 5, 23. [CrossRef]

18. SAS Institute Inc. Cary, NC, USA. 2012. Available online: https://www.sas.com/en_us/software/sas9.html (accessed on 2 March 2019).

19. Gittleman, J.L.; Gardner, P.C.; Haile, E.; Sampson, J.M.; Cigularov, K.P.; Ermann, E.D.; Stafford, P.; Chen, P.Y. CityCenter and Cosmopolitan Construction Projects, Las Vegas, Nevada: Lessons learned from the use of multiple sources and mixed methods in a safety needs assessment. J. Saf. Res. 2010, 41, 263-281. [CrossRef]

20. Bordas, R.M.; Davis, G.A.; Hopkins, B.L.; Thomas, R.E.; Rummer, R.B. Documentation of hazards and safety perceptions for mechanized logging operations in East Central Alabama. J. Agric. Saf. Health 2001, 7, 113-123. [CrossRef] 
21. Sønderstrup-Andersen, H.H.; Carlsen, K.; Kines, P.; Bjoerner, J.B.; Roepstorff, C. Exploring the relationship between leadership style and safety climate in a large scale danish cross-sectional study. Saf. Sci. Monit. 2011, 15, 1-9.

22. Lee, T. Assessment of safety culture at a nuclear reprocessing plant. Work Stress 1998, 12, 217-237. [CrossRef]

23. Lee, T.; Harrison, K. Assessing safety culture in nuclear power stations. Safety Sci. 2000, 34, 61-97. [CrossRef]

24. Wu, T.-C.; Liu, C.-W.; Lu, M.-C. Safety climate in university and college laboratories: Impact of organizational and individual factors. J. Saf. Res. 2007, 38, 91-102. [CrossRef]

25. Siu, O.-1.; Phillips, D.R.; Leung, T.-w. Age differences in safety attitudes and safety performance in Hong Kong construction workers. J. Saf. Res. 2003, 34, 199-205. [CrossRef]

26. Lipscomb, H.J.; Schoenfisch, A.L.; Cameron, W. Non-reporting of work injuries and aspects of jobsite safety climate and behavioral-based safety elements among carpenters in Washington state. Am. J. Ind. Med. 2015, 58, 411-421. [CrossRef]

27. Kjestveit, K.; Tharaldsen, J.; Holte, K.A. Young and strong: What influences injury rates within building and construction? Saf. Sci. Monit. 2011, 15, 1-15.

C 2019 by the authors. Licensee MDPI, Basel, Switzerland. This article is an open access article distributed under the terms and conditions of the Creative Commons Attribution (CC BY) license (http://creativecommons.org/licenses/by/4.0/). 